\title{
Impact of the COVID-19 Pandemic on the Academic Community Results from a survey conducted at University of Massachusetts Amherst
}

\author{
IMAN DEZNABI, TAMANNA MOTAHAR, ALI SARVGHAD, MADALINA FITERAU, and \\ NARGES MAHYAR, University of Massachusetts Amherst
}

\begin{abstract}
The COVID-19 pandemic has significantly impacted academic life in the United States and beyond. To gain a better understanding of its impact on the academic community, we conducted a large-scale survey at the University of Massachusetts Amherst. We collected multifaceted data from students, staff, and faculty on several aspects of their lives, such as mental and physical health, productivity, and finances. All our respondents expressed mental and physical issues and concerns, such as increased stress and depression levels. Financial difficulties seem to have the most considerable toll on staff and undergraduate students, while productivity challenges were mostly expressed by faculty and graduate students. As universities face many important decisions with respect to mitigating the effects of this pandemic, we present our findings with the intent of shedding light on the challenges faced by various academic groups in the face of the pandemic, calling attention to the differences between groups. We also contribute a discussion highlighting how the results translate to policies for the effective and timely support of the categories of respondents who need them most. Finally, the survey itself, which includes conditional logic allowing for personalized questions, serves as a template for further data collection, facilitating a comparison of the impact on campuses across the United States.
\end{abstract}

CCS Concepts: • Social and professional topics $\rightarrow$ User characteristics; • Applied computing $\rightarrow$ Consumer health;

Additional Key Words and Phrases: Survey, COVID-19, COVID-19 impacts, Academia

ACM Reference format:

Iman Deznabi, Tamanna Motahar, Ali Sarvghad, Madalina Fiterau, and Narges Mahyar. 2020. Impact of the COVID-19 Pandemic on the Academic Community Results from a survey conducted at University of Massachusetts Amherst. Digit. Gov. Res. Pract. 2, 2, Article 22 (December 2020), 13 pages.

https://doi.org/10.1145/3436731

\section{INTRODUCTION}

Major societal crises, such as the COVID-19 pandemic, transform people's lives in perceptible and imperceptible ways [1-3]. The COVID-19 pandemic has impacted academic life across the world [4]. Campus closures [5, 6], interrupted teaching and learning [7, 8], financial instability [9-12], and travel restrictions [13-15] are just a few examples of the problems faced by the academic community [16]. Many universities have implemented policies

M. Fiterau and N. Mahyar shared senior authorship.

Authors' addresses: I. Deznabi, A. Sarvghad, M. Fiterau, and N. Mahyar, College of Information and Computer Sciences, University of Massachusetts Amherst, 140 Governors Dr, Amherst, MA 01002, USA; emails: \{iman, asarv, mfiterau, nmahyar\}@cs.umass.edu; T. Motahar, University of Utah, 1234 Alameda Avenue, unit 20 Salt Lake City, UT 84102, USA; email: tamannam.ml@gmail.com.

Permission to make digital or hard copies of all or part of this work for personal or classroom use is granted without fee provided that copies are not made or distributed for profit or commercial advantage and that copies bear this notice and the full citation on the first page. Copyrights for components of this work owned by others than ACM must be honored. Abstracting with credit is permitted. To copy otherwise, or republish, to post on servers or to redistribute to lists, requires prior specific permission and/or a fee. Request permissions from permissions@acm.org.

(c) 2020 Association for Computing Machinery.

2639-0175/2020/12-ART22 $\$ 15.00$

https://doi.org/10.1145/3436731

Digital Government: Research and Practice, Vol. 2, No. 2, Article 22. Publication date: December 2020. 
and procedures to manage the spread of COVID-19. Collecting rich data is the first step toward understanding the depth and breadth of these changes [17].

To gain a better understanding [18] of the pandemic's impact on students, staff, and faculty's well-being [1922], we conducted a large-scale online survey with 1,785 respondents at the University of Massachusetts Amherst. The aim of this study was to determine the magnitude and types of impact that the COVID-19 pandemic had on different members of the academic community. In particular, we focused on dimensions such as health, levels of stress, levels of isolation, productivity, and financial stability, while asking for other hardships the pandemic may have caused for members of the academic community [23]. We hypothesized that, while the majority would be negatively impacted according to all criteria, there would be also differences between the impact areas for different categories of participants. For instance, we expected that undergraduate students, especially those with campus positions, would be more financially impacted than tenured faculty. We also expected that the segment of the campus community that requires access to facilities to perform research would be rendered a lot less productive than the rest. There is a significant exploratory aspect to this study in that, although some of the results were foreseeable, we did not limit our analysis to a fixed set of research questions and instead sought to pinpoint differences between categories of respondents and identify campus subpopulations that were severely impacted from different perspectives.

Universities across the world face many important decisions and challenges in managing the COVID-19 pandemic and mitigating the harm it has caused within their communities. For instance, universities need to decide which groups should have priority in testing for potential COVID-19 cases [24]. Our survey identifies the groups that are most at risk of COVID-19 and its complications (section 3.1). The administration can thus focus its efforts on testing the most vulnerable groups first. Other important decisions revolve around finance management and the allocation of financial support [25]. In Section 3.4, we analyze the financial impacts and concerns of different academic groups such that resources can be distributed to the groups that need them the most. Moreover, decisions should be taken to keep the same level of education [26,27] and engagement. We analyze the impacts of the pandemic on the educational experience, as well as the challenges it created for different groups, in Section 3.5. Universities also need to address issues related to mental well-being in the community [20,21], including how to conduct online counseling services. We analyse the impact on respondents' mental health in Sections 3.2 and 3.3. There are many different strategies that have been suggested for addressing each of these decisions [28-32].

Our ultimate objective is to use the insights presented in this article to help the university administration in their pandemic-related decision making. Our study is the first step toward the provision of support in the areas in which it is sorely needed and in the manner in which it brings the most benefit to the community.

We reached out to a representative subset of students, as well as all faculty and staff. We received 1,785 responses from our community, enabling us to ascertain the impact of the pandemic on our campus. In the rest of this report, we provide a summary of the most important findings of our survey. Reflecting on these findings, we also provide suggestions for addressing some of the identified issues.

\section{METHODOLOGY}

We conducted a large-scale online survey to collect data about the impact of the COVID-19 pandemic on the campus community at University of Massachusetts Amherst.

\subsection{Participants}

The survey's target population included current students, faculty, and staff of the University of Massachusetts Amherst. Participants were recruited with the university administration's help, which provided us with emails of a sample of undergraduates $(4,500)$, graduate students $(2,750)$, and all faculty and staff. We sent emails containing a description of the study, the consent agreement, and a link to the online survey to the selected subpopulation. Table 1 shows the breakdown of participants.

Digital Government: Research and Practice, Vol. 2, No. 2, Article 22. Publication date: December 2020. 
Table 1. The Gender and Campus Roles of the Survey Respondents

\begin{tabular}{lcccccccc}
\hline & $\begin{array}{c}\text { Student } \\
\text { (Ugrad) }\end{array}$ & $\begin{array}{c}\text { Student } \\
\text { (master's) }\end{array}$ & $\begin{array}{c}\text { Student } \\
\text { (Ph.D.) }\end{array}$ & Postdoc & Faculty & Staff & $\begin{array}{c}\text { Other/ } \\
\text { Unspecified }\end{array}$ & Total \\
\hline Female (trans + cis) & 227 & 86 & 146 & 13 & 154 & 465 & 28 & 1119 \\
Male (trans + cis) & 146 & 59 & 90 & 14 & 94 & 178 & 15 & 596 \\
Other/Unspecified & 14 & 9 & 10 & 2 & 6 & 25 & 4 & 70 \\
Total & 387 & 154 & 246 & 29 & 254 & 668 & 47 & 1785 \\
\hline
\end{tabular}

This study was approved by the Institutional Review Board of University of Massachusetts Amherst under protocol number 2044. All participants provided their informed consent by signing an online form before proceeding with the survey. Data were collected anonymously without IP addresses or GPS tracking.

\subsection{Survey Design and Flow}

We developed our survey based on review of prior research that considered the potential impacts of such global pandemics. Most significantly, the design of our questions were informed by well-known past survey designs such as Quality of life (WHO-QOL BREF) [33], WHO-5 well-being [34], Perceived stress (PSS-10) [35], and Depressive symptoms (PHQ-9) [36]. Our survey included 50 unique questions and was deployed via Qualtrics [37]. We collected data on a range of relevant topics, including (1) physical health; (2) stress; (3) socialization, loneliness, and family; (4) income and financial prospects; and (5) productivity. We conducted the survey between April 29, 2020, and July 20, 2020.

Taking the survey, participants first provided basic demographic data such as gender, age, and country or state of origin. Next, they moved to a multiple-choice question with 12 options including effects on health, levels of stress, levels of isolation, productivity, and financial stability to understand what aspects of their lives were impacted by the pandemic. All our survey participants responded to this "overview question." Based on the participants' responses to this overview question, we then asked more detailed questions for each of these aspects to better understand how they have been impacted. Table 2 shows all the options that respondents could choose in the overview question. The estimated completion time of the survey was 5-10 minutes based on pilot testing conducted among the study team members.

\subsection{Data Collection and Analysis}

We recorded all the participants answers to multiple choice questions as well as their textual comments and feedback. We received a total of 1,785 responses from the campus community. Table 1 shows the breakdown of the participants by gender and their campus role, which are faculty, staff, graduate students (Ph.D. and masters), and undergraduate students. To analyze the collected data, we used Qualtrics platform's built-in statistical, text analysis, and visualization tools.

\section{FINDINGS}

Based on the "overview" question, we found that for both health and finance, concerns about future risks affect a higher percentage of respondents than the actual realities at the time of the response. A majority of respondents reported high levels of stress, an impaired capacity in maintaining focus and motivation, and a reduction in physical activity. Moreover, two-thirds of the respondents expressed concern about their families.

Figure 1 summarizes the responses to the overview question that shows the impact on different aspects of respondents' lives, split by their role on campus. For instance, social isolation and loneliness disproportionately affected undergraduate students (Ugrads). Ph.D. students had the most trouble managing their work. Meanwhile, managing multiple responsibilities appears to be a problem for twice as many faculty and postdocs compared to 
Table 2. Options Available in the Overview Question Shown to All Participants

\begin{tabular}{l|c}
\hline Options in overview questions & Percentage of respondents \\
\hline I am having difficulty keeping focused and staying motivated. & $64.41 \%$ \\
I am worried about my family. & $64.24 \%$ \\
I am less physically active. & $57.37 \%$ \\
I am experiencing high levels of stress. & $53.09 \%$ \\
I am concerned about myself or my household being placed in financial difficulty. & $48.76 \%$ \\
Due to social distancing and self-isolation, I feel lonely. & $36.08 \%$ \\
I am heavily relying on social media for news and updates. & $34.26 \%$ \\
I am worried that I will get seriously ill. & $33.97 \%$ \\
I am having difficulty managing my work. & $33.45 \%$ \\
I am overwhelmed with juggling between many things (e.g. kids and work). & $15.08 \%$ \\
I am (or my household is) in financial difficulty. & \\
I am experiencing health issues. & $6.82 \%$ \\
\hline
\end{tabular}

Any number of options could be checked. The percentage of respondents who checked each option is indicated on the right.



Fig. 1. Normalized responses to the overview question, split by graduate and undergraduate students, postdocs, faculty, and staff.

students. Given these differences, we performed an in-depth analysis of the responses broken down by topic and campus roles-students, staff, postdocs, and faculty. Our findings are summarized in the following subsections.

\subsection{Physical Health}

Over the entire population of participants, only $6.82 \%$ reported that they are experiencing health issues due to the pandemic. However, $34.28 \%$ mentioned that they are worried that they will get seriously ill. When asked more detailed questions, this group reported their overall health condition as highly worsened (13\%) or worsened (65\%) following the onset of the pandemic. Figure 2 shows the breakdown of this data by role on campus. Of the survey participants, $43.23 \%$ reported suffering from chronic health conditions before the start of the pandemic. Figure 3 shows the breakdown of this data by role on campus. Asthma, depression, migraine, hypertension, and diabetes are among the most reported conditions. The relatively high percentages of respondents affected by chronic conditions call for closer attention to existing health issues when making policies related to the control of the pandemic.

Digital Government: Research and Practice, Vol. 2, No. 2, Article 22. Publication date: December 2020. 


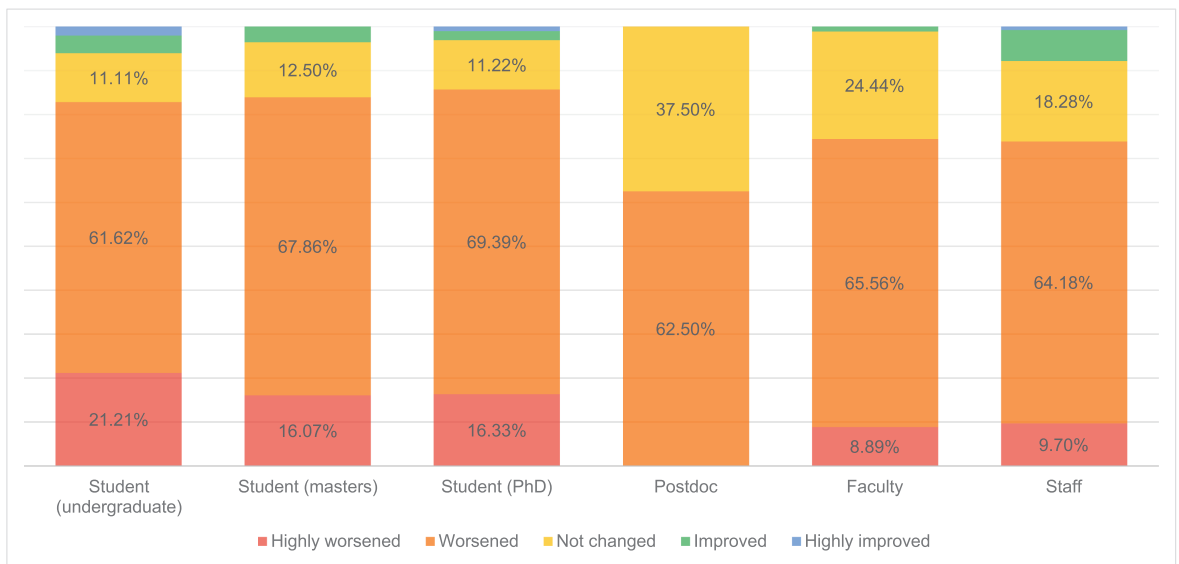

Fig. 2. Breakdown of level of impact on health of participants who were concerned about their health or were experiencing health issues.
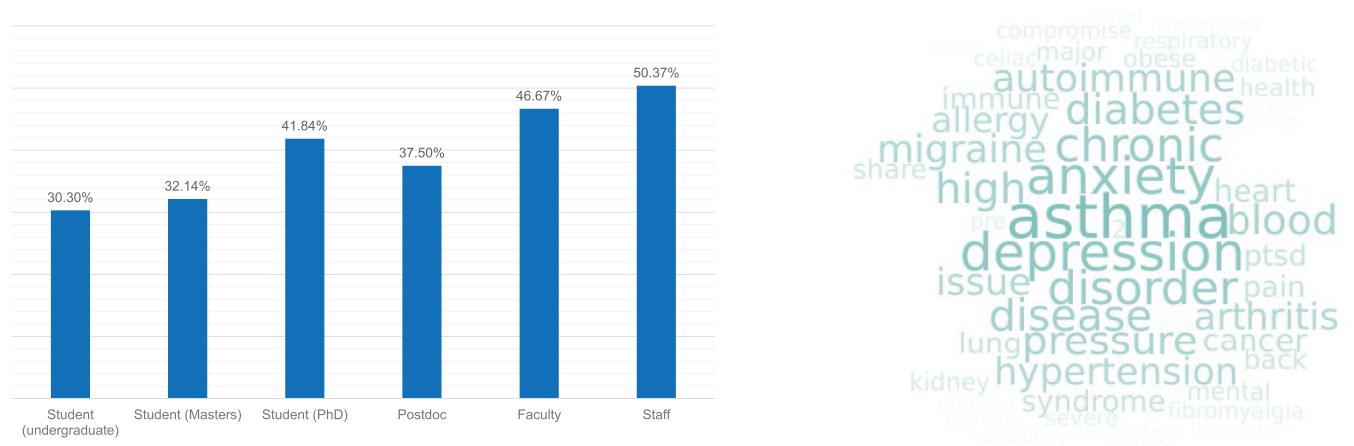

Fig. 3. (a) Percentage of participants in each role who reported having chronic conditions; (b) word cloud generated from the chronic conditions the participants reported as free-form text.

Among all groups, Ph.D. students had the highest percentage of respondents who experienced health issues (10.29\%), followed by master's students (7.33\%). Ph.D. students were also second in terms of being worried about becoming seriously ill, with $36.63 \%$. Furthermore, Ph.D. student respondents were the second group in terms of percentage of belonging to high-risk categories for COVID-19. However, undergraduate students had the lowest percentage (21.88\%) of respondents belonging to high-risk groups. Consequently, undergraduate respondents were also the least concerned about their health $(23.64 \%)$. Meanwhile, staff were the most concerned about their health; $39.01 \%$ reported that they are worried that they will get seriously ill, while only $6.19 \%$ actually experienced health issues related to COVID-19. Among the groups who were concerned about their well-being, staff had the highest percentage of respondents both in terms of belonging to high-risk categories for COVID-19 and suffering from chronic diseases. Faculty members also expressed moderate concern with getting seriously ill $(34.15 \%$ of respondents) despite having the second highest prevalence of chronic conditions.

\subsection{Stress}

Among our participants, $53.12 \%$ indicated that they are experiencing high levels of stress, which affected all surveyed groups. In our overview question, a higher percentage of Ph.D. students (63.37\%) selected this problem followed by undergraduate students $(58.42 \%)$, postdoc researchers and staff $(51.27 \%)$, master's students $(48.67 \%)$, 

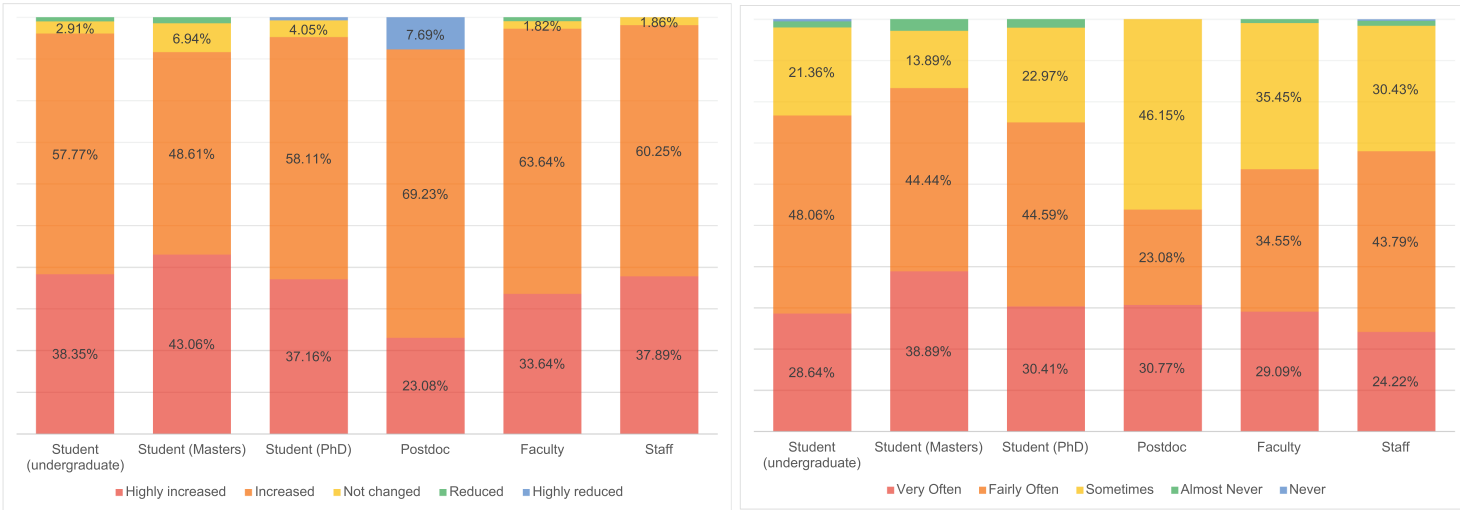

Fig. 4. (a) The breakdown of levels of increase in stress level based on the role in the campus among the participants who selected that they are experiencing high levels of stress. (b) The breakdown of how often participants who reported high levels of stress felt nervous during the pandemic.

and faculty members (45.12\%). Figure 4(a) shows a breakdown of how much the stress levels of each group increased due to the pandemic, and Figure 4(b) shows how often these participants felt nervous during the pandemic. Among the participants who reported an increase in stress levels, master's students both felt stressed more often and experienced higher levels of stress.

Staff members and postdocs were amid the groups least affected by stress and lack of socialization, as around $51.27 \%$ indicated they are experiencing high levels of stress. Among those, only $24.48 \%$ said that this feeling was felt very often-least of any group. Only $37.70 \%$ reported their loneliness levels increased due to social distancing, and among these respondents only $21 \%$ reported their loneliness levels as highly increased, which is the lowest percentage in any group.

Furthermore, faculty have the lowest percentage of respondents who experienced high levels of stress with $45.12 \%$ of faculty participants selecting this choice in the overview question. They also are the cohort who felt nervous or stressed the least amount of time among the respondents who experienced high levels of stress, only around $63.64 \%$ indicated that they felt nervous or stressed often or very often.

\subsection{Socialization, Loneliness, and Family}

All the participants reported impacts of the pandemic on their socialization and loneliness. Responses to our overview question showed that $47.11 \%$ of the participants across all groups reported loneliness due to social distancing and self-isolation. However, this affected different groups disproportionately, with students feeling the most impact, followed by staff and postdoc researchers and, finally, faculty members. Figure 5(a) shows a breakdown of increase in loneliness levels in these groups due to the pandemic. A higher percentage (47.95\%) of respondents who self-identified as extroverts reported highly increased levels of loneliness compared to only $27.40 \%$ of self-identified introverts. Figure 5(b) shows the breakdown of increase in loneliness levels according to whether the person considers themselves to be an extrovert or introvert. Furthermore, $64.28 \%$ of participants reported being worried about their family members, making this the second most selected choice after the ability to focus and stay motivated.

Loneliness was the second common problem among students, as the majority of the students reported an increased sense of loneliness and isolation (62.07\%). Loneliness seems to have had the worst impact on the undergraduate students, with $72.63 \%$ reporting that due to social distancing they feel lonely. A closer look at the comments provided by undergraduates shows that concerns related to transferring social and academic activi- 

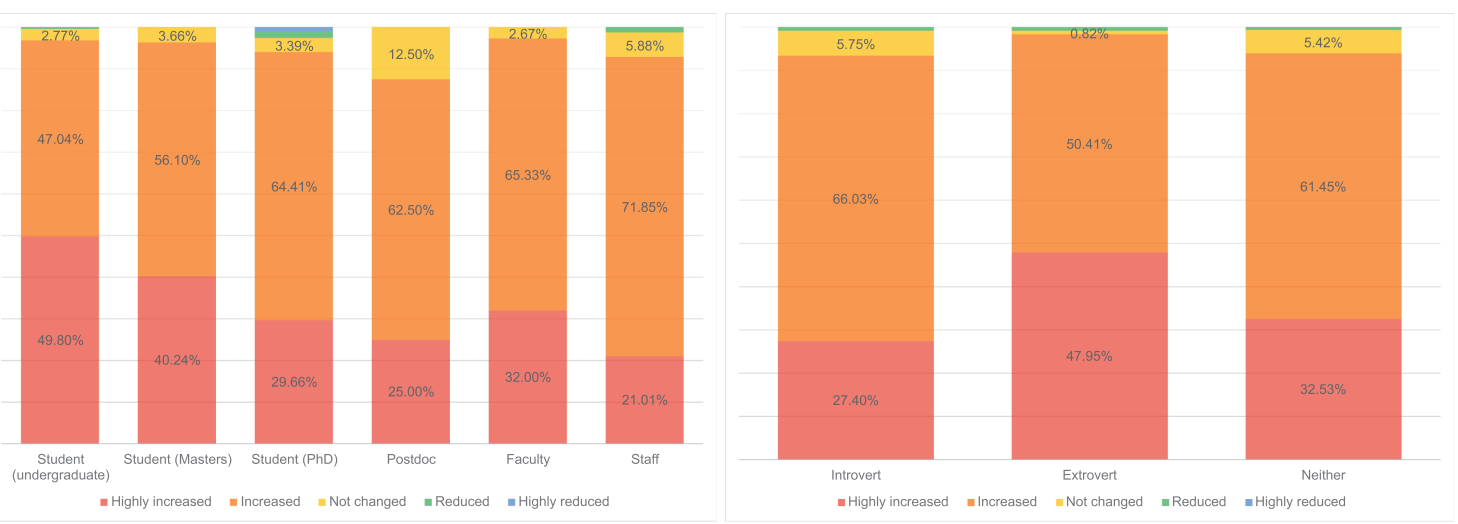

Fig. 5. (a) Breakdown of increase in loneliness levels by each group among participants who reported that they faced loneliness and socialization problems. (b) Breakdown of increase in loneliness levels according to whether the person considers themselves to be an extrovert or introvert.

ties online represent the most emerging theme, followed by uncertainty about the future of the job market and financial hardships.

Moreover, the most common problem for university staff and postdoc researchers was the concern about their family members, with $67.66 \%$, the highest among any group; $40.96 \%$ reported having family members at COVID-19 hot spots. ${ }^{1}$

However, faculty members were the least impacted group in terms of socialization and loneliness problems where only $30.49 \%$ reported these problems in the overview question, and among those only $32 \%$ indicated their loneliness levels as highly increased.

\subsection{Income and Financial Prospects}

Over the entire survey population, concerns about potential financial impact far outstripped the actual financial impact experienced by the respondents. While less than $15.09 \%$ reported that they have been actually impacted financially, $48.79 \%$ of respondents reported concerns about potential impact. Responses were vastly different depending on the role on campus, with students being significantly more affected than faculty. We further explored the financial impact of the pandemic for the respondents who reported that they were affected or concerned about being financially challenged according to our overview question. We call this the "financially concerned" cohort of the survey population, and it comprises a total of 895 respondents, around half of the total number of survey respondents. Over half of the financially concerned reported suffering some loss of income or experiencing a worse financial situation than before the outbreak. A small percentage experienced a significantly worse situation. A troubling aspect is that very few respondents in this cohort believed their jobs were safe: Only $10.61 \%$ of financially concerned respondents considered themselves out of danger of losing their source of income. Forty-two of the respondents even reported that they are in danger of becoming homeless. The undergraduate students were by far the most financially impacted survey population, $24.93 \%$ of which reported that they, or someone from their household, were placed in financial difficulty by the pandemic. They are closely followed by the master's and Ph.D. students, with $23.33 \%$ and $20.58 \%$, respectively, reporting financial difficulties at the time of the survey. Concern about future impact is widespread, affecting 40-50\% in every student category. Amid the financially concerned students, over $65 \%$ of the master's students and over $57 \%$ of the Ph.D. students reported a worsened or highly worsened financial situation. Four of five financially concerned undergraduates

${ }^{1}$ COVID-19 hot spots were different depending on the time when the survey was taken.

Digital Government: Research and Practice, Vol. 2, No. 2, Article 22. Publication date: December 2020. 
Table 3. Breakdown of Aspects of Work Being Impacted for Each Campus Role

\begin{tabular}{|c|c|c|c|c|c|c|c|c|}
\hline \# & Factors affecting productivity & Overall & $\begin{array}{l}\text { Student } \\
\text { (Ugrad) }\end{array}$ & $\begin{array}{c}\text { Student } \\
\text { (master's) }\end{array}$ & $\begin{array}{l}\text { Student } \\
\text { (Ph.D.) }\end{array}$ & Postdoc & Faculty & Staff \\
\hline 1 & $\begin{array}{l}\text { Can not finish my study due to lack of } \\
\text { access to lab equipment }\end{array}$ & $17.79 \%$ & $18.75 \%$ & $12.20 \%$ & $25.61 \%$ & $50.00 \%$ & $23.68 \%$ & $1.64 \%$ \\
\hline 2 & $\begin{array}{l}\text { Can not finish my study due to lack of } \\
\text { access to human subjects }\end{array}$ & $11.35 \%$ & $4.17 \%$ & $12.20 \%$ & $19.51 \%$ & $37.50 \%$ & $21.05 \%$ & $1.64 \%$ \\
\hline 3 & Fewer meetings with my advisor/s & $33.13 \%$ & $43.75 \%$ & $56.10 \%$ & $45.12 \%$ & $12.50 \%$ & $5.26 \%$ & $4.92 \%$ \\
\hline 4 & $\begin{array}{l}\text { Difficulties in meeting } \\
\text { collaborators/coworkers }\end{array}$ & $33.44 \%$ & $40.63 \%$ & $46.34 \%$ & $30.49 \%$ & $50.00 \%$ & $39.47 \%$ & $11.48 \%$ \\
\hline 5 & $\begin{array}{l}\text { Difficulties in consulting with (and } \\
\text { getting advice from) peers/coworkers }\end{array}$ & $29.14 \%$ & $37.50 \%$ & $29.27 \%$ & $40.24 \%$ & $25.00 \%$ & $10.53 \%$ & $13.11 \%$ \\
\hline 6 & $\begin{array}{l}\text { Lack of socialization with } \\
\text { peers/coworkers }\end{array}$ & $47.85 \%$ & $48.96 \%$ & $73.17 \%$ & $70.73 \%$ & $62.50 \%$ & $18.42 \%$ & $14.75 \%$ \\
\hline 7 & Inability to access computing facilities & $13.50 \%$ & $11.46 \%$ & $24.39 \%$ & $17.07 \%$ & $25.00 \%$ & $7.89 \%$ & $6.56 \%$ \\
\hline 8 & $\begin{array}{l}\text { Poor internet connections and/or lack } \\
\text { of quiet working place }\end{array}$ & 44.48 & $48.96 \%$ & $48.78 \%$ & $48.78 \%$ & $87.50 \%$ & $55.26 \%$ & $16.39 \%$ \\
\hline 9 & Not Applicable & $33.13 \%$ & $34.38 \%$ & $17.07 \%$ & $13.41 \%$ & $12.50 \%$ & $26.32 \%$ & $75.41 \%$ \\
\hline
\end{tabular}

Lack of socialization and interaction with peers as well as diminishing opportunities for mentorship and advice were major contributors to the decrease in productivity, especially amid students and postdocs, while the poor working conditions (poor internet connection and/or lack of quiet working space) has a detrimental impact on a high percentage of respondents in all categories except the staff.

reported that they or someone in their household have already lost income, as did three of five non-Ph.D. graduate students and almost half of the Ph.D. students. Worse yet, almost a fifth of the financially concerned Ph.D. students were uncertain about whether they will be able to keep their homes.

However, while compared to the overall study group, a smaller percentage of staff and postdocs (10.73\%) report actual financial difficulty, this cohort was the category with the highest percentage of concerned respondents about their future financial situation (60.36\% expressed concern). Over $47 \%$ of financially concerned staff members and postdoc researchers have a worse financial situation than before the outbreak. Only $6.52 \%$ of the financially concerned staff feel certain that their household will not lose a main source of income.

Faculty also have, by far, the lowest percentage of respondents whose households were placed in financial difficulty $(3.25 \%)$. Compared to the study population, a lower percentage of faculty expressed concern for the future (39.02\%). Given that many of the faculty are tenured and also considering the age of the respondents, we conclude that concern amid the junior faculty is widespread. We also note that over 10 times more respondents are concerned than affected, which is a similar trend to what was observed amid the staff. In fact, few of the financially concerned faculty consider their jobs secure, with only $8.16 \%$ of them stating they are not in danger of being laid off. Additionally, over $41 \%$ of financially concerned faculty reported a worse financial situation than before the outbreak. On a more positive note, the faculty are the least in danger of homelessness.

\subsection{Productivity}

The pandemic and subsequent campus closures have taken a toll on the productivity of the community. According to our overview question, almost two-thirds of all respondents indicated having difficulty keeping focused and staying motivated. A third of the respondents indicated difficulty in managing work. A third of the respondents indicated they were overwhelmed with juggling many things, such as childcare and work. We selected the most impacted cohort from the perspective of productivity, namely, 332 respondents ( $18.6 \%$ of all the participants) who had difficulty managing work, keeping focused, and reported being less active.

For the cohort of respondents whose productivity was impacted, we also studied which aspects of their work were affected, as shown in Table 3. We found that poor working conditions - poor internet connection and/or 
lack of quiet working space have a detrimental impact on a high percentage of respondents in all categories except the staff. The most common problem among our student respondents was the ability to stay motivated and focused, with $80.66 \%$ of $\mathrm{Ph}$.D. students reporting difficulties in this respect. This group is closely followed by undergraduate students (79.95\%) and master's students (77.33\%), according to our overview question. However, undergraduates and master's students have the lowest percentage of respondents who reported being overwhelmed with juggling between many things, $23.1 \%$ and $23.33 \%$, respectively.

Over $70 \%$ of graduate students in the affected cohort reported a lack of socialization with peers or co-workers to be a contributing factor to their decreased productivity. A related factor, difficulties in meeting collaborators or coworkers was also indicated by over $40 \%$ of undergraduates and $45 \%$ of master's students. Slightly less affected appear to be the Ph.D. students, with 30\% indicating difficulties in meeting collaborators. Over $45 \%$ of Ph.D. students and $43 \%$ of undergraduates in this cohort reported having fewer meetings with their advisors, but the most affected category, from the perspective of advisor meetings, was the master's students, $56 \%$.

Based on the overview question, the staff have the lowest percentage of respondents with difficulty in managing their work. Even amid the productivity-affected cohort, staff seem to not be as severely impacted, with just over a quarter reporting highly worsened productivity. Furthermore, postdocs, staff, and faculty have the highest percentage of respondents whose productivity was not lowered.

Conversely, the highest percentage of respondents overwhelmed with juggling between many things is amid the faculty $(45.12 \%)$. Of the faculty, $54.88 \%$ also reported having difficulty focusing and staying motivated. In the productivity-affected cohort, almost $40 \%$ of the faculty reported difficulties in meeting collaborators or coworkers. Like postdocs, the faculty are also affected by the lack of access to lab equipment (about 1 in 4 respondents) and human subjects (about 1 in 5 respondents).

\section{DISCUSSION}

Our findings pinpoint the negative impacts of the COVID-19 pandemic on all students, staff, and faculty's physical and mental well-being, productivity, prosperity, and social lives. All our respondents reported experiencing health-related issues such as a considerable increase in stress, depression, and anxiety. Our findings highlight the need for immediate provision of measures to assist the campus community with their increased physical and mental health problems. The current model of care is largely built around on-campus in-person services, but the current crisis shows the necessity of building the infrastructure to make services and resources available online. For instance, campuses should invest more in telemedicine [38, 39], enabling remote consulting and monitoring of patients, as well as facilitate online social interactions between community members to encourage the mental and physical benefits associated with social connections [1, 2, 40,41]. The importance of such measures is even more pressing in light of the fact that $43 \%$ of our survey respondents reported suffering from chronic health conditions.

As also shown in previous research [42-44] we found that the manifestation and magnitude of other issues vary between the three studied groups. Financial difficulties seem to have the most notable impact on staff and undergraduate students. Staff also reported considerable concerns about their future job security. Productivity issues were mostly reported by graduate students and faculty. Graduate students principally attribute the toll on their productivity to the side effects of social isolation, such as loneliness and lack of access to on-campus research equipment and resources. However, for faculty, the problem mostly stems from the blurred lines between homelife and work-life, superimposing rest and leisure spaces to productivity and connectivity.

Respondents' comments on strategies to cope with isolation, social distancing, and stress provide insight into delivering measures and services to alleviate future crises. Several of the respondents mentioned online socialization and community building services such as virtual volunteering and support groups as measures for coping with isolation. Many participants also mentioned indoor activities, such as cooking, reading, exercise, meditation, and learning new skills, as coping mechanisms. Respondents' comments suggest that providing

Digital Government: Research and Practice, Vol. 2, No. 2, Article 22. Publication date: December 2020. 
productivity, creativity, and connectivity apps and online tools could help the campus community better cope with loneliness and isolation.

To the best of our knowledge, the present work is the first study that investigates the many ways in which the COVID-19 pandemic impacted academic communities, comparing the impact on different groups.

Our study contributes to the literature by highlighting the differences between, and the major challenges faced by various academic groups in the face of the pandemic. Another contribution is the survey itself, which is geared toward understanding these challenges in the academic community. One of the features of the survey is the conditional logic behind the questions shown to each respondent, with in-depth questions being displayed in the areas of concern for that particular respondent. This personalized setup enabled us to drill into each issue without overloading the study participants. The dataset collected from the 1,785 participants is sufficient to draw statistically significant conclusions and will be used for further analysis.

Our results follow the trends that previous research reported in the general population in terms of effects on mental health and isolation [21, 42, 45], financial impacts [46, 47], physical health [48], and productivity [49]. We also show the impacts that were specific to different groups in the academic community. For instance, we show that the pandemic impacted the graduate students' productivity more than any other mentioned academic group. University staff were the most worried about their financial situation. Our analysis indicates clear areas where interventions are needed and we provided actionable suggestions to university administrators based on the analysis.

This study is helpful to a wide range of stakeholders. For university administrators, it provides a clearer picture of the different groups' needs and challenges, based on which they can make informed decisions concerning interventions to combat the effects of the pandemic. If acted upon, then these insights can ultimately benefit the community as a whole, including the survey respondents. For the research community, this survey constitutes a template that can be used to compare results across universities and countries.

This study has some limitations as well. First, the survey is limited to the academic community at University of Massachusetts Amherst, and it is unclear if the results will generalize to other universities and communities. Although collecting data from other universities as well would have been preferable, it would not have allowed us to collect data in a timely manner. This was essential given the urgent need to gain an understanding of the impacts of the pandemic and promptly act on this understanding. However, some trends seen here, might be relevant to other universities, as suggested by previous research on the general population. Second, there is a potential selection bias, since the respondents volunteered their information following an invitation to the survey. Furthermore, all the questions are based on self-evaluation tests, which, while widely used, also introduce a source of bias when participants report on their own experiences [50].

\section{CONCLUSION}

Determining the most affected aspects of peoples' lives is the first step in moving toward mitigating the negative effects of a global pandemic. Finding out the various ways in which people are affected and the magnitude of the issues they face will indicate the aspects that they would need the most support. Through this survey, we collected data from students, faculty, and staff at the University of Massachusetts Amherst and highlighted the problems that each cohort is facing regarding the COVID-19 pandemic. We hope that our results help in identifying the most pressing issues and devising appropriate policies to mitigate the pandemic impact on the academic community.

\section{REFERENCES}

[1] Louise C. Hawkley, Ronald A. Thisted, and John T. Cacioppo. 2009. Loneliness predicts reduced physical activity: Cross-sectional \& longitudinal analyses. Health Psychol. 28, 3 (2009), 354.

[2] Kimberly A. Van Orden, Emily Bower, Julie Lutz, Caroline Silva, Autumn M. Gallegos, Carol A. Podgorski, Elizabeth J. Santos, and Yeates Conwell. 2020. Strategies to promote social connections among older adults during 'social distancing' restrictions. Am. F. Geriatr. Psychiatr. 28, 5 (2020). https://www.ncbi.nlm.nih.gov/pmc/articles/PMC7233208/.

Digital Government: Research and Practice, Vol. 2, No. 2, Article 22. Publication date: December 2020. 
[3] Gideon Lichfield. 2020. We're Not Going Back to Normal. Technology Review. Retrieved from https://cutt.ly/FyeUQhq.

[4] Office of Elementary \& Secondary Education United States Department of Education. 2020. Fact Sheet: Impact of COVID-19 on Assessments and Accountability under the Elementary and Secondary Education Act. Government report. March 12, 2020.

[5] Mike Baker, Anemona Hartocollis, and Karen Weise. 2020. First U.S. Colleges Close Classrooms as Virus Spreads; More Could Follow. Retrieved from https://www.nytimes.com/2020/03/06/us/coronavirus-college-campus-closings.html.

[6] Shoko Kawano and Masayuki Kakehashi. 2015. Substantial impact of school closure on the transmission dynamics during the pandemic flu H1N1-2009 in Oita, Japan. PLoS One 10, 12 (2015), e0144839.

[7] Lee Kyungmee. 2020. Coronavirus: Universities Are Shifting Classes Online-But It's Not as Easy as It Sounds. Retrieved from https://theconversation.com/coronavirus-universities-are-shifting-classes-online-but-its-not-as-easy-as-it-sounds- 133030.

[8] Charles Hodges, Stephanie Moore, Barb Lockee, Torrey Trust, and Aaron Bond. 2020. The Difference Between Emergency Remote Teaching and Online Learning. Retrieved from https://er.educause.edu/articles/2020/3/the-difference-between-emergency-remoteteaching-and-online-learning.

[9] Andrew Atkeson. 2020. What Will Be the Economic Impact of covid-19 in the US? Rough Estimates of Disease Scenarios. Technical Report. National Bureau of Economic Research.

[10] Mohammad Yamin. 2020. Counting the cost of COVID-19. Int. F. Inf. Technol. (2020), 1-7.

[11] Annie Nova. 2020. They Were Struggling to Repay Their Student Loans before the Pandemic: Now It'll Get Worse. Retrieved from https://www.cnbc.com/2020/06/27/how-covid-19-has-made-the-student-loan-crisis-even-worse.html.

[12] United States Department of Education. 2020. Secretary DeVos Directs FSA to Stop Wage Garnishment, Collections Actions for Student Loan Borrowers, Will Refund More Than \$1.8 Billion to Students, Families. Retrieved from https://www.ed.gov/news/pressreleases/secretary-devos-directs-fsa-stop-wage-garnishment-collections-actions-student-loan-borrowers-will-refund-more-18billion-students-families.

[13] Juliet Bedford, Delia Enria, Johan Giesecke, David L. Heymann, Chikwe Ihekweazu, Gary Kobinger, H. Clifford Lane, Ziad Memish, Myoung-don Oh, Anne Schuchat, et al. 2020. COVID-19: Towards controlling of a pandemic. The Lancet 395, 10229 (2020), 1015-1018

[14] A. Salcedo and G. Cherelus.2020. Coronavirus Travel Restrictions, across the Globe. Retrieved from https://www.nytimes.com/article/ coronavirus-travel-restrictions.html.

[15] Centers for Disease Control and Prevention. 2020. Considerations for Travelers-Coronavirus in the US. Retrieved from https://www. cdc.gov/coronavirus/2019-ncov/travelers/travel-in-the-us.html.

[16] Pradeep Sahu. 2020. Closure of universities due to Coronavirus Disease 2019 (COVID-19): Impact on education and mental health of students and academic staff. Cureus 12, 4 (2020).

[17] Richard L. Daft and Robert H. Lengel. 1986. Organizational information requirements, media richness and structural design. Manage. Sci. 32, 5 (1986), 554-571.

[18] Office for Civil Rights United States Department of Education. 2020. Fact Sheet: Addressing the Risk of COVID-19 in Schools While Protecting the Civil Rights of Students. Government Report.

[19] Yu-Tao Xiang, Yuan Yang, Wen Li, Ling Zhang, Qinge Zhang, Teris Cheung, and Chee H. Ng. 2020. Timely mental health care for the 2019 novel coronavirus outbreak is urgently needed. Lancet Psychiatr. 7, 3 (2020), 228-229.

[20] Paula Odriozola-González, Álvaro Planchuelo-Gómez, María Jesús Irurtia, and Rodrigo de Luis-García. 2020. Psychological effects of the COVID-19 outbreak and lockdown among students and workers of a Spanish university. Psychiatr. Res. 290 (2020), 113108. DOI : $10.1016 /$ j.psychres.2020.113108

[21] Wenjun Cao, Ziwei Fang, Guoqiang Hou, Mei Han, Xinrong Xu, Jiaxin Dong, and Jianzhong Zheng. 2020. The psychological impact of the COVID-19 epidemic on college students in China. Psychiatr. Res. 287 (2020), 112934. DOI : 10.1016/j.psychres.2020.112934

[22] Remya Lathabhavan and Mark Griffiths. 2020. First case of student suicide in India due to the COVID-19 education crisis: A brief report and preventive measures. Asian f. Psychiatr. 53 (2020), 102202. https://www.ncbi.nlm.nih.gov/pmc/articles/PMC7297156/.

[23] Andrew DePietro. 2020. Here's a Look at the Impact of Coronavirus (COVID-19) on Colleges and Universities in the U.S. Retrieved from https://www.forbes.com/sites/andrewdepietro/2020/04/30/impact-coronavirus-covid-19-colleges-universities/\#3eff44d461a6.

[24] Douglas Belkin and Yoree Koh. 2020. To Test or Not to Test? Colleges Face Decision as Students and Coronavirus Arrive on Campus. Retrieved from https://www.wsj.com/articles/as-campuses-reopen-colleges-face-tough-call-on-covid-19-testing-11599050006.

[25] Christina Capatides. 2020. Colleges across the U.S. Brace for Impact as the Coronavirus Batters Their Already Tenuous financial Ground. Retrieved from https://www.cbsnews.com/news/us-colleges-coronavirus-impact-finances/.

[26] Abdalellah O. Mohmmed, Basim A. Khidhir, Abdul Nazeer, and Vigil J. Vijayan. 2020. Emergency remote teaching during Coronavirus pandemic: The current trend and future directive at Middle East College Oman. Innov. Infrastruct. Solut. 5, 3 (2020), 1-11.

[27] Pragashnie Govender, Deshini Naidoo, and Jacqueline M. van Wyk. 2020. A 3Ts (teaching in troubled times) response to COVID-19 in South Africa. Clin. Teach. 17, 4 (2020), 427-429.

[28] Sayed Zeesan Haider and D. B. More. 2020. Strategies for tackling the financial challenges facing colleges and universities during Covid-19 \& its impact on higher education. Purakala 31, 39 (2020), 280-285.

[29] Centers for Disease Control and Prevention. 2020. Considerations for Institutions of Higher Education. Retrieved from https://www. cdc.gov/coronavirus/2019-ncov/community/colleges-universities/considerations.html.

Digital Government: Research and Practice, Vol. 2, No. 2, Article 22. Publication date: December 2020. 
[30] Andrew Smalley. 2020. Higher Education Responses to Coronavirus (COVID-19). Retrieved from https://www.ncsl.org/research/ education/higher-education-responses-to-coronavirus-covid-19.aspx.

[31] Esteve Corbera, Isabelle Anguelovski, Jordi Honey-Rosés, and Isabel Ruiz-Mallén. 2020. Academia in the time of COVID-19: Towards an ethics of care. Plann. Theory Pract. 21, 2 (2020), 191-199. https://www.tandfonline.com/doi/full/10.1080/14649357.2020.1757891.

[32] Joseph Crawford, Kerryn Butler-Henderson, Jürgen Rudolph, Bashar Malkawi, Matt Glowatz, Rob Burton, Paulo Magni, and Sophia Lam. 2020. COVID-19: 20 countries' higher education intra-period digital pedagogy responses. F. Appl. Learn. Teach. 3, 1 (2020), 1-20.

[33] World Health Organization. Division of Mental Health and Prevention of Substance Abuse. 1998. WHOQOL: Measuring quality of life. World Health Organization. Programme on mental health : Whoqol user manual. Technical documents.

[34] WHO. 1998. Wellbeing measures in primary health care/the depcare project. World Health Organization Consensus Meeting. Regional Office. Stockholm.

[35] Sheldon Cohen, Tom Kamarck, and Robin Mermelstein. 1983. A global measure of perceived stress. F. Health Soc. Behav. 24, 4 (1983), 385-396. DOI : $10.2307 / 2136404$

[36] Robert L. Spitzer, Kurt Kroenke, Janet B. W. Williams, Patient Health Questionnaire Primary Care Study Group, et al. 1999. Validation and utility of a self-report version of PRIME-MD: The PHQ primary care study. F. Am. Med. Assoc. 282, 18 (1999), 1737-1744.

[37] Qualtrics. 2020. Retrieved from https://www.qualtrics.com/.

[38] Vidushi Mahajan, Tanvi Singh, and Chandrika Azad. 2020. Using telemedicine during the COVID-19 pandemic. Ind. Pediatr. 57, 7 (2020), 658-661.

[39] Si-qian Zheng, Li Yang, Peng-xiang Zhou, Hui-bo Li, Fang Liu, and Rong-sheng Zhao. 2020. Recommendations and guidance for providing pharmaceutical care services during COVID-19 pandemic: A China perspective. Res. Soc. Admin. Pharm. 17, 1 (2020), $1819-1824$. DOI: $10.1016 /$ j.sapharm.2020.03.012

[40] Tjalling Jan Holwerda, Dorly J. H. Deeg, Aartjan T. F. Beekman, Theo G. van Tilburg, Max L. Stek, Cees Jonker, and Robert A. Schoevers. 2014. Feelings of loneliness, but not social isolation, predict dementia onset: Results from the Amsterdam Study of the Elderly (AMSTEL). 7. Neurol. Neurosurg. Psychiatr. 85, 2 (2014), 135-142.

[41] Philippe Courtet, Emilie Olié, Christophe Debien, and Guillaume Vaiva. 2020. Keep socially (but not physically) connected and carry on: Preventing suicide in the age of COVID-19. F. Clin. Psychiatr. 81, 3 (2020).

[42] Mark É. Czeisler, Rashon I. Lane, Emiko Petrosky, Joshua F. Wiley, Aleta Christensen, Rashid Njai, Matthew D. Weaver, Rebecca Robbins, Elise R. Facer-Childs, Laura K. Barger, et al. 2020. Mental health, substance use, and suicidal ideation during the COVID-19 pandemic-United States, June 24-30, 2020. Morbid. Mortal. Week. Rep. 69, 32 (2020), 1049.

[43] Ioulia Solomou and Fofi Constantinidou. 2020. Prevalence and predictors of anxiety and depression symptoms during the COVID-19 pandemic and compliance with precautionary measures: Age and sex matter. Int. F. Environ. Res. Publ. Health 17, 14 (2020), 4924.

[44] Rodolfo Rossi, Valentina Socci, Dalila Talevi, Sonia Mensi, Cinzia Niolu, Francesca Pacitti, Antinisca Di Marco, Alessandro Rossi, Alberto Siracusano, and Giorgio Di Lorenzo. 2020. COVID-19 pandemic and lockdown measures impact on mental health among the general population in Italy. Front. Psychiatr. 11 (2020), 790. https://www.frontiersin.org/article/10.3389/fpsyt.2020.00790/full.

[45] Christoph Pieh, Sanja Budimir, and Thomas Probst. 2020. The effect of age, gender, income, work, and physical activity on mental health during coronavirus disease (COVID-19) lockdown in Austria. f. Psychosom. Res. 136 (2020), 110186. DOI : 10.1016/j.jpsychores. 2020.110186

[46] Alexander Dietrich, Keith Keuster, Gernot J. Müller, and Raphael Schoenle. 2020. News and Uncertainty about COVID-19: Survey Evidence and Short-Run Economic Impact. FRB of Cleveland Working Paper No. 20-12, Apr 2020. https://papers.ssrn.com/abstract= 3573123.

[47] Esteban M. Aucejo, Jacob French, Maria Paola Ugalde Araya, and Basit Zafar. 2020. The impact of COVID-19 on student experiences and expectations: Evidence from a survey. F. Publ. Econ. 191 (2020), 104271. DOI : 10.1016/j.jpubeco.2020.104271

[48] Andrew Clark, Mark Jit, Charlotte Warren-Gash, Bruce Guthrie, Harry H. X. Wang, Stewart W. Mercer, Colin Sanderson, Martin McKee, Christopher Troeger, Kanyin L. Ong, et al. 2020. Global, regional, and national estimates of the population at increased risk of severe COVID-19 due to underlying health conditions in 2020: A modelling study. The Lancet Global Health 8, 8 (2020), e1003-e1017.

[49] M. Bishr Omary, Jeetendra Eswaraka, S. David Kimball, Prabhas V. Moghe, Reynold A. Panettieri, Kathleen W. Scotto, et al. 2020. The COVID-19 pandemic and research shutdown: Staying safe and productive. F. Clin. Invest. 130, 6 (2020).

[50] Marion Devaux and Franco Sassi. 2016. Social disparities in hazardous alcohol use: Self-report bias may lead to incorrect estimates. Eur. F. Publ. Health 26, 1 (2016), 129-134.

Received July 2020; revised November 2020; accepted November 2020

Digital Government: Research and Practice, Vol. 2, No. 2, Article 22. Publication date: December 2020. 